\title{
Antifungal Activity of Fruit Extracts of Different Water Chestnut Varieties
}

\author{
Mohammad ANOWAR RAZVY', Ahmad HUMAYAN KABIR², Mohammad AMINUL HOQUE' \\ ${ }^{1}$ University of Rajshahi, Department of Agronomy and Agricultural Extension, Rajshahi 6205, Bangladesh \\ ${ }^{2}$ Flinders University, School of Biological Sciences, SA 5042, Australia; abmad.kabir@flinders.edu.au
}

\begin{abstract}
The antifungal activity of three varieties (red, green and wild) of water chestnut fruit extracts was studied against a number of fungal species. A strong antifungal activity of ethanol and petroleum extract was found against the treated fungi resulting remarkable inhibition zone in comparison to both Dithane- $\mathrm{M}_{45}$ fungicide and control. It has also been evident that wild variety of water chestnut was comparatively more efficient in respect to antifungal activity compared to the red and green variety of the same plant.
\end{abstract}

Keywords: antifungal activity, fruit extract, inhibition zone, solvents

\section{Introduction}

Nature has been a source of medicinal agents for thousands of years and an impressive number of modern drugs have been isolated from natural sources and many of them are based on their use in traditional medicine. Medicinal plants have been used for centuries before the advent of orthodox medicine. Leaves, flowers, stems, roots, seeds, fruit and bark of plant are the constituents of herbal medicines. Secondary metabolites (photochemical) of plant are extensively found at different levels in various medicinal plants and used in herbal medicine to treat diverse ailments such as cough, malaria, wounds, toothache and rheumatism diseases (Exarchou et al., 2002) and protection of crops. In recent years, the growing demand for herbal product has led to a quantum jump in volume of plant materials traded within and across the countries. Species used in traditional medicine continue to be the most reliable source for the discovery of useful compounds and screening of plants (Ben et al., 1992; Broekaert et al., 1997; Dubery et al., 1999; Hanawa et al., 1992; Kruger and Manion, 1994; Mohamed and Sehgal, 1997; Pernas et al., 2000). It has opened another source of compounds useful inhibitory activities against different microbes. Hence there is a constant need to establish and develop antimicrobial drugs from natural origin that are much safe, reliable and less expensive.

Fungi are significant destroyers of crop, food stuffs and grains. A significant portion of the agricultural products in the world has become unfit for human consumption due to mycotoxins contamination of grains, especially those produced by species of Aspergillus (Chandra and Sarbhoy, 1997; Devi et al., 2001; Janardhana et al., 1999). The main toxic effects are carcinogenicity, genotoxicity, terratogenicity, nephrotoxicity, hepatotoxicity, reproductive disorders and immune-suppression (Desjardins et al., 2000; Lacey, 1988). A large portion of world population is living below poverty line in the developing and underdeveloped countries. People are also suffering from health problems associated with consuming mycotoxin contaminated grains and cereals (Majumder et al., 1997).

Though effective control of different fungi can be achieved by the use of synthetic chemical fungicides, but these are not environmentally safe. Thus, there is a need to search for alternative compound to protect the damage of crop, store grains or cereals and various diseases or infections without toxicity problems that are eco-friendly and expensive. Plant extracts of many higher plants have been reported to exhibit antibacterial, antifungal and insecticidal properties under laboratory trails (Bouamama $e t$ al., 2006; Ergene et al., 2006; Kiran and Raveesha, 2006; Mohana and Raveesha, 2006; Okigbo and Ogbonnaya, 2006; Satish et al., 1999; Shariff et al., 2006). Plant metabolites and plant-based pesticides appear to be one of the better alternatives as they are known to have minimal environmental danger to consumers in contrast to the synthetic pesticides (Verma and Dubey, 1999).

The present study was undertaken in order to investigate the antimicrobial properties of different varieties of water chestnut fruits found on rainy season in Bangladesh. Antifungal activities of different extracts were tested against seven fungi by using disc diffusion technique. Because it is basically a quantitative or semi-quantitative test which indicates the sensitivity or resistance of fungus to the test material.

\section{Materials and methods}

\section{Plant materials}

Mature fresh fruits of three varieties of Trapa spp for extraction were used as plant material. One wild variety (Trapa quadrispinosa Roxb.) and two cultivars (Green and Red) of Trapa bispinosa Roxb were collected from the 
62

experimental field of Botanical Garden at Rajshahi University, Bangladesh. These plants were previously collected from Niamatpur and Sapahar Upazila, Naogaon, Bangladesh.

\section{Fungal strain}

Total seven pathogenic fungal strains, namely Penicilium sp, Aspergillus flavus, Aspergillus niger, Fusarium species, Aspergillus fumigatius and Candida albicans, were used for the present sensitivity test.

\section{Test materials}

Three solvents (aqua's, ethanol and petroleum ether) were used for the antifungal activity study. The concentrations of test sample in different extract were $100 \mu \mathrm{g} / \mathrm{l}, 200$ $\mu \mathrm{g} / \mathrm{l}$ and $250 \mu \mathrm{g} / \mathrm{l}$, respectively. The standard antifungal reagent was Dithane- $\mathrm{M}_{45}$ fungicides at a fixed concentration $(100 \mu \mathrm{g} / \mathrm{l})$ used as positive control.

\section{Preparation of culture media}

Potato dextrose agar (PDA) media was used to perform the antifungal activity test as well for the subculture of the test organism. The composition of the culture media was $200 \mathrm{~g}$ peeled and sliced potato, $40 \mathrm{~g}$ dextrose, $20 \mathrm{~g}$ agar and $1000 \mathrm{ml}$ distilled water.

\section{Preparation of the test plates}

About $10 \mathrm{ml}$ distilled water was poured in several clean test tubes and plugged with cotton. Then $6 \mathrm{ml}$ of the medium was poured carefully in the medium sized petridishes. The petri-dishes were rotated several times, firstly clockwise followed by anticlockwise to assure homogenous thickness of the medium and allowed to cool and solidify at $30^{\circ} \mathrm{C}$. The test tubes containing distilled water were inoculated with fresh culture of the test fungi and were shaken gently to form a uniform suspension of the organism because of their high prevalence sporulation process. Then a piece of cotton was immerged in the test tubes with the help of individual glass rod. Then the medium was gently rubbed and the cotton was discarded. Finally the plates were stored in a refrigerator $\left(4^{\circ} \mathrm{C}\right)$ for whole night.

\section{Preparation of discs}

Two types of antifungal discs were prepared for antifungal screening. One was the sample disc and another type discs was the standard disc prepared by antifungal reagent Dithane- $\mathrm{M}_{45}$ fungicide. Sample discs were sterilized (BBL, Cocksrvile, USA) and filter paper discs ( $5 \mathrm{~mm}$ diameter) were taken in a blank petri-dishes. Sample solution of desired amount was applied on the discs with the help of micropipette in aseptic condition. The discs were left for a few minutes in an aseptic condition for complete removal of solvent and standard discs was prepared with the concentration of (Dithane- $\mathrm{M}_{45}$ fungicides) $100 \mu \mathrm{g} /$ disc.

\section{Placement of the discs and incubation}

Both the dried crude extract discs and standard disc were placed gently on the solidified agar plates sealed with the test pathogenic fungus ensuring contact with the medium by the sterile forceps. The plates were then kept in a refrigerator at $4{ }^{\circ} \mathrm{C}$ for 24 hours in order to provide sufficient time to diffuse the antibiotics into the medium. After that the plates were incubated at $37.5^{\circ} \mathrm{C}$ for 24 hours in an incubator. After incubation, the antibacterial activities of the test samples were determined by measuring the diameter of inhibitory zones (millimeter) with a transparent scale.

\section{Results and discussion}

Different concentrations of aqua's, ethanol and petroleum extract of water chestnut fruit extract were tested against fungal growth. In was observed that all three varieties of water chestnut exhibited some sort of antifungal activity resulting inhibition zone ranging from $1.1 \pm 0.03$ $\mathrm{mm}$ to $9.9 \pm 0.71 \mathrm{~mm}$ in diameter. Highest inhibition zone $(9.9 \pm 0.71 \mathrm{~mm})$ was found against Aspergillus flavus when treated with $250 \mu \mathrm{g} / \mathrm{disc}$ of ethanol extract of wild variety (Fig. 1). It was revealed that both ethanol and petroleum extracts seemed to be more efficient to inhibit the growth of all Aspergillus species compared to aqua's extract (Tab. 1). It was reported that ethanolic extract of Anogeissus leiocarpus and Terminalia avicennioides is more efficient than the methanolic, chloroform, or aqueous extracts against all the test fungi (Mann et al., 2008). In comparison, wild variety showed highest antifungal activity against all the fungi used in this study, which reveals the presence of toxic substances in wild water chestnut compared to red and green. It was interesting to be noted that petroleum extract

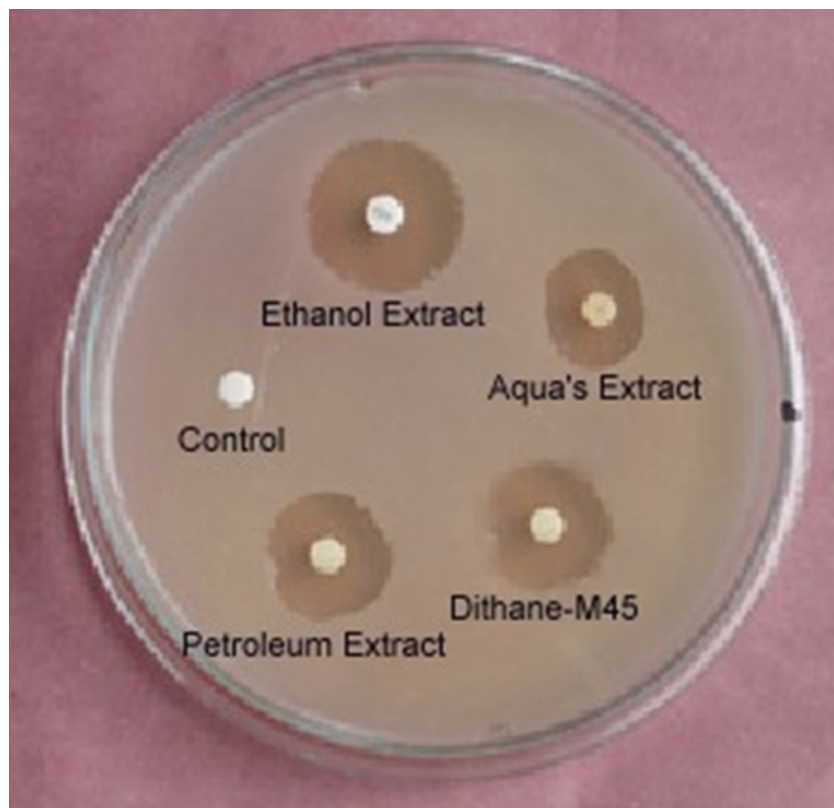

Fig. 1. Antifungal activity of water chestnut (wild variety) 
found to be more efficient than other two solvents against Penicilium sp., Fusarium sp. and Candida albicans (Tab. 2). Lowest growth $(4.2 \pm 0.07 \mathrm{~mm})$ was recorded against $C a n-$ dida albicans while highest $(7.1 \pm 0.58 \mathrm{~mm})$ was obtained against Penicilium sp. (Tab. 2). Hypothetically increase in the antifungal activity of any extract supposed to be found by increase concentration, which was not observed in this study. Application of plant extract to inhibit fungal or bacterial growth is a common practice. In this study, fruits of water chestnut especially the wild variety found to be efficient against some fungal genotypes and it also indicates the potential inhibitory effect on other fungi or molds (Tab. 1 and Tab. 2). Use of different parts of plant has also been noticed in many literatures. Leaves extract of Pistacia lentiscus and Pistacia atlantica have been proved to be very effective against eight bacteria, five moulds and yeast by disc diffusion method (Benhammou et al., 2008). Plant extracts also act as an inhibiting agent against some bacteria. It was reported that Caryophyllus aromaticus and induced antifungal materials of Citrus fruits in relation to the enhancement of decay resistance by heat and ultraviolet treatments. Journal of Agricultural and Food Chemistry 40:1217-1221.

Benhammou N, Bekkara FA, Panovska TK (2008). Antioxidant and antimicrobial activities of the Pistacia lentiscus and Pistacia atlantica extracts. African Journal of Pharmacy and Pharmacology 2:22-28.

Bouamama H, Noel T, Villard J, Benharref A, Jana M (2006). Antimicrobial activities of the leaf extracts of two Moroccan Cistus L. species. Journal of Ethnopharmacology 104:104107.

Broekaert WF, Cammue BPA, Debolle MFC, Thevissen K, Desamblanx GW, Osborn RW (1997). Antimicrobial peptides from plants. Critical Reviews in Plant Sciences 16:297-323.

Chandra R, Sarbhoy AK (1997). Production of Aflatoxins and Zearalenone by the toxigenic fungal isolates obtained from stored food grains of commercial crops. Indian

Tab. 2. Evaluation of in vitro antifungal activity against other fungi

\begin{tabular}{|c|c|c|c|c|c|c|c|c|c|c|}
\hline \multirow{3}{*}{ PM } & \multirow{3}{*}{$\begin{array}{c}\text { Ext. } \\
\mu \mathrm{g} / \mathrm{disc}\end{array}$} & \multicolumn{9}{|c|}{ Disc/Zone of inhibition $(\mathrm{mm})$} \\
\hline & & \multicolumn{3}{|c|}{ Penicilium sp } & \multicolumn{3}{|c|}{ Fusarium species } & \multicolumn{3}{|c|}{ Candida albicans } \\
\hline & & 100 & 200 & 250 & 100 & 200 & 250 & 100 & 200 & 250 \\
\hline \multirow{3}{*}{$\mathrm{V}_{1}$} & AQ & $1.1 \pm 0.03$ & $1.7 \pm 0.01$ & $1.9 \pm 0.01$ & $1.3 \pm 0.12$ & $2.2 \pm .02$ & $2.0 \pm 0.22$ & $2.4 \pm 0.16$ & $2.9 \pm 0.09$ & $2.6 \pm 0.04$ \\
\hline & ET & $3.0 \pm 0.22$ & $2.0 \pm 0.22$ & $3.0 \pm 0.22$ & $1.5 \pm 0.34$ & $2.0 \pm 0.32$ & $2.0 \pm 0.21$ & $3.0 \pm 0.30$ & $3.0 \pm 0.06$ & $3.0 \pm 0.01$ \\
\hline & PE & $4.0 \pm 0.01$ & $3.0 \pm 0.34$ & $3.1 \pm 0.30$ & $3.1 \pm 0.54$ & $4.0 \pm 0.41$ & $3.0 \pm 0.07$ & $3.0 \pm 0.45$ & $4.0 \pm 0.09$ & $4.0 \pm 0.42$ \\
\hline \multirow{3}{*}{$\mathrm{V}_{2}$} & AQ & $1.3 \pm 0.11$ & $1.3 \pm 0.11$ & $1.2 \pm 0.28$ & $1.7 \pm 0.70$ & $2.2 \pm 0.11$ & $2.9 \pm 0.11$ & $2.3 \pm 0.31$ & $2.3 \pm 0.34$ & $2.1 \pm 0.55$ \\
\hline & ET & $4.3 \pm 0.19$ & $4.3 \pm 0.51$ & $5.2 \pm 0.35$ & $4.1 \pm 0.24$ & $4.7 \pm 0.44$ & $3.8 \pm 0.23$ & $4.5 \pm 0.43$ & $3.3 \pm 0.41$ & $3.1 \pm 0.21$ \\
\hline & PE & $5.1 \pm 0.08$ & $3.9 \pm 0.22$ & $4.8 \pm 0.22$ & $4.4 \pm 0.54$ & $3.8 \pm 0.11$ & $4.1 \pm 0.29$ & $4.3 \pm 0.22$ & $4.1 \pm 0.44$ & $3.8 \pm 0.07$ \\
\hline \multirow{3}{*}{$\mathrm{V}_{3}$} & AQ & $2.3 \pm 0.28$ & $2.3 \pm 0.44$ & $2.8 \pm 0.38$ & $3.1 \pm 0.23$ & $3.5 \pm 0.10$ & $3.6 \pm 0.11$ & $2.5 \pm 0.21$ & $2.9 \pm 0.21$ & $2.9 \pm 0.22$ \\
\hline & ET & $6.1 \pm 0.21$ & $5.9 \pm 0.24$ & $5.9 \pm 0.11$ & $5.3 \pm 0.66$ & $5.2 \pm 0.25$ & $5.5 \pm 0.05$ & $4.2 \pm 0.07$ & $4.9 \pm 0.07$ & $4.8 \pm 0.36$ \\
\hline & PE & $7.1 \pm 0.58$ & $6.8 \pm 0.34$ & $6.5 \pm 0.25$ & $5.2 \pm .08$ & $5.1 \pm 0.44$ & $4.9 \pm 0.08$ & $6.1 \pm 0.35$ & $6.3 \pm 0.02$ & $6.4 \pm 0.11$ \\
\hline \multirow{3}{*}{$\mathrm{NC}$} & AQ & + & + & + & + & + & + & + & + & + \\
\hline & ET & + & + & + & + & + & + & + & + & + \\
\hline & PE & + & + & + & + & + & + & + & + & + \\
\hline
\end{tabular}

$\mathrm{PM}=$ Plant Materials, $\mathrm{AQ}=$ Aqua's extract, ET = Ethanol Extract, $\mathrm{PE}=$ Petroleum Extract, $\mathrm{PC}=$ Positive control (Disc containing Antifungal reagent), NC= Negative control (Disc containing only solvent), $(+)=$ Growth, $(-)=$ no sensitivity, $V_{1}=$ Green, variety, $V_{2}=$ Red variety, $V_{3}=$ Wild variety, Inhibition zone excluding disc $(5$ mm) space

Syzygyum joabolanum extracts found to be promising for inhibiting the growth of Pseudomonas aeruginosa (Nascimento et al., 2000).

\section{Conclusions}

It could be concluded that fruit extract of water chestnut has great prospective as antimicrobial compounds against microorganisms. This may open a new window in the treatment of infectious diseases caused by resistant microbes.

\section{References}

Ben YS, Rodov V, Kim JJ, Carmeli S (1992). Preformed and
Phytopathology 50:458-68.

Desjardins AE, Manandhar G, Plattner RD, Maragos CM, Shrestha K, McCormick SP (2000). Occurrence of Fusarium species and mycotoxins in Nepalese Maize and Wheat and the effect traditional processing method on mycotoxin levels. Journal of Agricultural and Food Chemistry 48:1377-1383.

Devi KT, Mayo MA, Reddy G, Emmanuel KE, Larondelle Y, Reddy DVR (2001). Occurrence of Ochratoxin A in black pepper, coriander, ginger and turmeric in India. Food Additives Contamination 18:830-835.

Dubery IA, Louw AE, Van Heerden FR (1999). Synthesis and evaluation of 4-(3-methyl-2-butenoxy) isonitrosoacetophenone, a radiation-induced stress metabolite in Citrus. Phytochemistry 50:983-989. 
64

Ergene A, Guler P, Tan S, Mirici S, Hamzaoglu E, Duran A (2006). Antibacterial and antifungal activity of Heracleum sphondylium subsp. artvinense. African Journal of Biotechnology 5:1087-1089.

Exarchou V, Nenadis N, Tsimidou M, Gerothanassis IP, Troganis A, Boskou D (2002). Antioxidant activities and phenolic composition of extracts from Greek oregano, Greek sage and summer savory. Journal of Agricultural and Food Chemistry 50:5294-5299.

Nascimento GGF, Locatelli J, Freitas PC, Silva GL (2000) Antibacterial activity of plant extracts and phytochemicals on antibioticresistant bacteria. Brazilian Journal of Microbiology 31:247-256.

Hanawa F, Tahara S, Mizutani J (1992). Antifungal stress compounds from Veratrum grandiflorum leaves treated with cupric chloride. Phytochemistry 31:3005-3007.

Janardhana GR, Raveesha KA, Shetty HS (1999). Mycotoxin contamination of maize grains grown in Karnataka (India). Food Chemical Toxicology 37:863-868.

Kiran B, Raveesha KA (2006). Antifungal activity of seed extract of Psoralea corylifolia L. Plant Disease Research 20:213-215

Kruger BM, Manion PD (1994). Antifungal compounds in aspen: Effect of water stress. Canadian Journal of Botany $72: 454-460$.

Lacey J (1988). The microbiology of cereal grains from areas of Iran with a high incidence of oesophageal cancer. Journal of Stored Product Research 24:39-50.

Majumder UK, Gupta M, Mukhopadhyay DK (1997). Effect of mycotoxins isolated from Penicillium nigricans on glucose6-phosphate dehydrogenase. Indian Journal of Experimental Biology 35:1233-1236.
Mann A, Banso A, Clifford LC (2008). An antifungal property of crude plant extracts from Anogeissus leiocarpus and Terminalia avicennioides. Tanzania Journal of Health Research 10:34-38.

Mohamed F, Sehgal OP (1997). Characteristics of pathogenesisrelated proteins induced in Phaseolusvulgaris cv. Pinto following viral infection. Journal of Phytopathology. 145:49-58.

Mohana DC, Raveesha KA (2006). Anti-bacterial activity of Caesalpinia coriaria (Jacq.) Willd. against plant pathogenic Xanthomonas pathovars: an eco-friendly approach. Journal of Agricultural Technology 2:317-327.

Okigbo RN, Ogbonnaya UO (2006). Antifungal effects of two tropical plant leaf extracts (Ocimum gratissimum and Aframomum melegueta) on post harvest yam (Dioscorea spp.) rot. African Journal of Biotechnology 5:727-731.

Pernas M, Sanchez-Monge R, Salcedo G (2000). Biotic and abiotic stress can induce cystatin expression in chestnut. FEBS Letters 467:206-210.

Satish S, Raveesha KA, Janardhana GR (1999). Antibacterial activity of plant extracts on phytopathogenic Xanthomonas campestris pathovarst. Letter in Applied Microbiology 28:145-147.

Shariff N, Sudarshana MS, Umesha S, Hariprasad P (2006). Antimicrobial activity of Rauvolfia tetraphylla and Physalis minima leaf and callus extracts. African Journal of Biotechnology 5:946-950.

Verma J, Dubey NK (1999). Prospective of botanical and microbial products as pesticides of tomorrow. Current Science 76:172-179. 